\title{
Redox-induced proton insertion and desertion of zircon-type neodymium chromate(V)
}

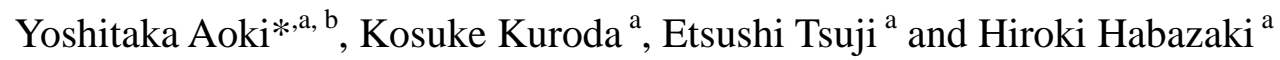

$a$ Faculty of Engineering, Hokkaido University, N13W8 Kita-ku, Sapporo, 060-8628 Japan. $b$

PRESTO, Japan Agency of Science and Technology, Saitama, 332-0012 Japan.

\section{Corresponding: Yoshitaka Aoki}

Tel : +81-11-706-6752

E-mail : y-aoki@eng.hokudai.ac.jp

Key word: high valence state oxide, proton insertion reaction, PCFC 


\begin{abstract}
Redox transformation of $\mathrm{NdCr}^{\mathrm{V}} \mathrm{O}_{4}$ involved by insertion/desertion of protons was examined by XRD, XPS, in situ FT-IR and fuel cell tests. It was found that $\mathrm{NdCrO}_{4}$ caused bulk reduction with $\mathrm{H}_{2}$ gas at around $400^{\circ} \mathrm{C}$, changing to amorphous $\mathrm{Nd}(\mathrm{III})-\mathrm{Cr}$ (III) hydroxide phase. This hydroxide phase, however, could recover to the original zircon type oxide phase by air oxidation at the same temperature region. Proton-conducting ceramic fuel cells having $\mathrm{NdCrO}_{4}$ film as an interlayer between cathode and electrolyte was fabricated and the cell was confirmed to exhibit remarkable power generation giving rise to OCV of more than $1.0 \mathrm{~V}$ at $500^{\circ} \mathrm{C}$. It was speculated that the interlayer facilitates proton transfer from electrolyte to cathode because redox cycling of $\mathrm{NdCrO}_{4}$ and the corresponding hydroxide was driven by the high proton chemical potential at the interface with electrolyte and plenty of oxygen in cathode gases.
\end{abstract}




\section{Introduction}

Reactivity of transition metal oxides consisting of high valence state metal ions, such as $\mathrm{Cr}^{\mathrm{V}}, \mathrm{Fe}^{\mathrm{VI}}, \mathrm{Co}^{\mathrm{IV}}, \mathrm{Cu}^{\mathrm{III}}$ and so on has been focus of the many investigations because of its roles in super ion battery [1,2], biological reactions [3-5] and heterogeneous catalytic processes [6-8]. The unusual reactivity of these metal oxides is due primarily to the relatively high redox potential of high valence state metal ions. Rare earth chromates, $\mathrm{RECrO}_{4}$ (RE: rare earth metal(III)), are a group of compounds comprising from tetrahedral $\mathrm{Cr}^{\mathrm{V}} \mathrm{O}_{4}{ }^{3-}$ oxoanions, and are thermally stable at temperatures below $600^{\circ} \mathrm{C}$ in ambient atmosphere $[9,10]$. Previously, we reported that zircon-type $\mathrm{NdCrO}_{4}$ undergoes unique redox reaction with gaseous alcohol, accompanied by insertion and desertion of protons into the solids $[11,12]$. It was reduced with methanol gases at around $270^{\circ} \mathrm{C}$, changing to the low-crystalline, $\mathrm{Cr}$ (III) hydroxide phase by attracting hydrogen atoms from methanol [11, 12]. The hydroxide phase, however, was easily oxidized in air at the same temperature to recover to the original $\mathrm{NdCrO}_{4}$ phase [11]. This unique reactivity may disclose that $\mathrm{NdCrO}_{4}$ possesses bulk diffusivity of proton and electron. Such a mixed proton and electron conducting material is rather rare $[13,14]$, but is attractive as reversible electrode materials for hydrogen rechargeable battery, hydrogen pump devices and so on. Thus it is of fundamental and of technological interest to understand this unique behavior of the $\mathrm{Cr}(\mathrm{V})$ oxides.

Calcium chromate, $\mathrm{CaCr}^{\mathrm{VI}} \mathrm{O}_{4}$, is hexavalent chromium oxide, having the same crystal structure as $\mathrm{NdCr}^{\mathrm{V}} \mathrm{O}_{4}$. Standard redox potential of $\mathrm{Cr}(\mathrm{VI} \rightarrow \mathrm{III})(1.33 \mathrm{~V}$ vs NHE) [15] is almost same as that of $\mathrm{Cr}(\mathrm{V} \rightarrow \mathrm{III})\left(1.32 \mathrm{~V}\right.$ vs NHE) [3]. Hence, $\mathrm{CaCrO}_{4}$ is a good target to 
evaluate the reactivity of $\mathrm{NdCrO}_{4}$ by comparison method. Herein, we examined the redox behavior of these two high valence state chromates through the reactions with $\mathrm{H}_{2}$ gas. Bulk reduction does not take place in $\mathrm{CaCrO}_{4}$ because the poor electrical conductivity and relatively small free volume do not allow the enhanced diffusion of electron and proton. Moreover, it is demonstrated redox cycling of $\mathrm{NdCrO}_{4}$ and the corresponding hydroxide form proceeds under cathodic conditions of operating proton-conducting ceramics fuel cell (PCFC). The unique reactivity may attribute to the coexistence of the relatively large interstitial spaces and singular $\mathrm{Cr}(\mathrm{V})$ oxidation state in $\mathrm{NdCrO}_{4}$.

\section{Experimental}

Synthesis method of a single phase zircon-type $\mathrm{NdCrO}_{4}$ was described elsewhere [16]. Zircon-type $\mathrm{CaCrO}_{4}$ samples were also prepared by the similar method. In briefly, $\mathrm{Nd}\left(\mathrm{CH}_{3} \mathrm{COO}\right)_{3}\left(99.9 \%\right.$ purity, Kanto) or $\mathrm{Ca}\left(\mathrm{CH}_{3} \mathrm{COO}\right)_{2}\left(99.9 \%\right.$ purity, Kanto) and $\mathrm{CrO}_{3}$ (99.9\% purity, Kanto) powders were dissolved into Milli-Q water at a stoichiometric Nd/Cr or $\mathrm{Ca} / \mathrm{Cr}$ molar ratio. The solutions were heated at $140^{\circ} \mathrm{C}$ in order to evaporate water and then once heated at $400^{\circ} \mathrm{C}$ for $1 \mathrm{~h}$ in air, and thus the precursor powders were obtained. For $\mathrm{NdCrO}_{4}$, the precursor was calcined at $580^{\circ} \mathrm{C}$ for $3 \mathrm{~h}$ in air. In case of $\mathrm{CaCrO}_{4}$, the precursor was calcined at $750^{\circ} \mathrm{C}$ for $3 \mathrm{~h}$ in air. The purity of the samples was determined by chemical titration, XPS, and XRD. The specific surface area of the sample powder was measured by nitrogen adsorption (BET method) at $-198^{\circ} \mathrm{C}$. The reaction of $\mathrm{NdCrO}_{4}$ with $\mathrm{H}_{2}$ was carried out in a continuous-flow tubular fixed-bed reactor of a quartz tube (7.0 mm in diameter); $100 \mathrm{mg}$ 
of sample powder was used as the reactant. Before the reaction, the temperature of the sample was raised at $10^{\circ} \mathrm{C} \min ^{-1}$ in the ambient atmosphere, and maintained at $250-500^{\circ} \mathrm{C}$ for $1 \mathrm{~h}$ under an $\operatorname{Ar}$ (99.99 \% pure) flow $100 \mathrm{~cm}^{3} \mathrm{~min}^{-1}$. The reaction was started by flowing pure hydrogen gas at $100 \mathrm{~cm}^{3} \mathrm{~min}^{-1}$. The samples after the reduction were isothermally oxidized in the same reactor by switching the flow of hydrogen to dry air.

The XRD patterns were measured by the Rigaku diffractometer with a monochromator. The XPS measurements were carried out by a JEOL JPS-9010MC. Fourier-transform infrared (FT-IR) spectra were recorded in a diffuse reflectance mode by using a JASCO FT/IR-350 spectrometer. The in situ FT-IR measurements were conducted with a gas-sealed optical cell with an antireflective glass window to acquire the spectra under the controlled atmosphere and temperature. The cell was smaller than $10 \mathrm{~cm}^{3}$ and equipped with an electronic furnace. Thermogravimetry (TG) was conducted by using a Shimazu DTG-30A.

Proton conducting ceramic fuel cells (PCFC) having $\mathrm{NdCrO}_{4}$ cathode interlayer were fabricated. $\mathrm{BaZr}_{0.1} \mathrm{Ce}_{0.7} \mathrm{Y}_{0.2} \mathrm{O}_{3-\delta}$ (BZCY) was prepared by a solid state reaction method. Stoichiometric amounts of high-purity barium carbonate, zirconium oxide, cerium oxide, and yttrium oxide powders (all from Kanto Chemicals) were mixed and calcined at $1050{ }^{\circ} \mathrm{C}$ in air for $10 \mathrm{~h}$ to form the perovskite phase. After confirming a single phase by XRD, the ceramic powders were pressed into pellets by CIP at $100 \mathrm{MPa}$ and sintered at $1500{ }^{\circ} \mathrm{C}$ in air for $20 \mathrm{~h}$ to form a dense BZCY pellet ( $>85 \%$ of ideal density) as an electrolyte. Pt paste was applied on one face as anode and fired at $800{ }^{\circ} \mathrm{C}$ for $1 \mathrm{~h}$ to form porous Pt electrodes. Porous layer of $\mathrm{NdCrO}_{4}$ paste prepared by mixing the as-prepared powders and $\alpha$-terpineol (Aldrich) was 
screen printed on the another face of BZCY electrolyte and, subsequently, porous layer of $\mathrm{La}_{0.8} \mathrm{Sr}_{0.2} \mathrm{Co}_{0.2} \mathrm{Fe}_{0.8} \mathrm{O}_{3-\delta}$ (LSCF) paste (Alsrich) was screen printed as a cathode and annealed at $600{ }^{\circ} \mathrm{C}$ for $1 \mathrm{~h}$. Thus, a single cell consisting of a Pt anode (100 nm), a BZCY electrolyte film $(1 \mathrm{~mm}), \mathrm{NdCrO}_{4}$ cathode interlayer $(10 \mu \mathrm{m})$ and a LSCF cathode $(20 \mu \mathrm{m})$ was obtained. The electrode active area was $0.283 \mathrm{~cm}^{2}$. Two gold wires were connected to each electrode as current leads. The cell was mounted on an alumina supporting tube for fuel-cell testing at $400-700{ }^{\circ} \mathrm{C}$ with humidified hydrogen $\left(3\right.$ vol $\% \mathrm{H}_{2} \mathrm{O}$ ) as fuel and stationary air as oxidant. The fuel-cell performances were measured using a Solartron Potentiostat/Galvanostat (Model 1283A).

\section{Results and Discussion}

Figure 1a shows XRD patterns of $\mathrm{NdCrO}_{4}$ powders (specific surface areas of $4.0 \mathrm{~m}^{2} \mathrm{~g}^{-1}$ ) reacted with $\mathrm{H}_{2}$ gas for 20 min at elevated temperatures. Zircon type structure of $\mathrm{NdCrO}_{4}$ is deformed by reacting with $\mathrm{H}_{2}$ gas at temperatures above $380^{\circ} \mathrm{C}$. The XRD patterns still retains the features of zircon type phase in addition to a broad hallo peak of amorphous phase at around $33^{\circ}$ after 20 min reaction with $\mathrm{H}_{2}$ at $380^{\circ} \mathrm{C}$, but the longer reduction further deteriorates the zircon structure and develops the amorphous state (Fig. 1b). Figure 1d shows a TEM image of $\mathrm{NdCrO}_{4}$ specimens and the corresponding selected-area electron diffraction (SAED) patterns from different particles, revealing crystalline and amorphous phases coexist in the reduced for 20 min (Fig. 1d). These features clearly show that $\mathrm{NdCrO}_{4}$ phase transforms to amorphous state by reduction with $\mathrm{H}_{2}$ at $380^{\circ} \mathrm{C}$. 
Cr 2p XPS spectra reveal Cr(V) ions are reduced to $\mathrm{Cr}(\mathrm{III})$ state after the 20 min reaction at $380^{\circ} \mathrm{C}$ (Fig. 2a). The $2 p_{3 / 2}$ peak position of as-prepared $\mathrm{NdCrO}_{4}(578.5 \mathrm{eV})$ is in agreement with the values of the $\mathrm{Cr}(\mathrm{V})$ oxides [16]. The $2 \mathrm{P}_{3 / 2}$ peak clearly shifts to lower energy side and is located at around $576.3 \mathrm{eV}$ after the reaction. This value is similar to that of the $\mathrm{Cr}$ (III) oxides $\mathrm{Cr}_{2} \mathrm{O}_{3}(576.6 \mathrm{eV})$ [17]. $\mathrm{NdCrO}_{4}$ is reduced with $\mathrm{H}_{2}$ at $380^{\circ} \mathrm{C}$.

Figure 3a shows a TG curve of $\mathrm{NdCrO}_{4}$ samples, measured in pure $\mathrm{H}_{2}$ gas. It keeps the weight below $400^{\circ} \mathrm{C}$ but abruptly losses $8 \%$ weight at around $450^{\circ} \mathrm{C}$ as transforming to perovskite-type $\mathrm{NdCrO}_{3}$ by releasing one oxygen atom a molecular. $\mathrm{NdCrO}_{4}$ must show 0.77 wt\% mass gain if it is reduced by the following hydrogenation reaction.

$$
\mathrm{NdCrO}_{4}+2 \mathrm{H}^{+}+2 \mathrm{e}^{-} \leftrightarrows \quad \mathrm{NdCrO}_{4} \mathrm{H}_{2} \quad \text { Eq. } 1
$$

When it is exposed to $\mathrm{H}_{2}$ atmosphere at $380^{\circ} \mathrm{C}$, the weight of $\mathrm{NdCrO}_{4}$ is logarithmically increased and the reaction is in stationary after $1800 \mathrm{~s}$ so as to gain about $0.6 \mathrm{wt} \%$ (Fig. 3b). This value is close to the mass gain by Eq. 1 . In conclusion, the charge loss by chromium reduction is compensated by proton insertion into the $\mathrm{NdCrO}_{4}$ lattice instead of losing the lattice oxygen at the temperatures below $400^{\circ} \mathrm{C}$.

The amorphous phase prepared by $1 \mathrm{~h}$ reduction at $380^{\circ} \mathrm{C}$ is reversibly changed to zircon phase by isothermal oxidation in air (Fig. 1b). Sharp XRD peaks of zircon-type phase are recovered after 10 min oxidation, indicating that the degraded structure was quickly restored by oxidation.

In situ FT-IR spectroscopy clearly reveals evolution of hydroxyl groups in $\mathrm{NdCrO}_{4}$ by hydrogen reduction (Fig. 4a). The sharp peak near $3350 \mathrm{~cm}^{-1}$ is the noise from detector. The 
broad IR peaks at around $3500 \mathrm{~cm}^{-1}$ are assigned to the stretching mode of hydroxyl group (-OH). The $-\mathrm{OH}$ group immediately develops as exposing to $\mathrm{H}_{2}$ gas and the peak intensity is continuously increasing for $10 \mathrm{~min}$. These features reveal that $\mathrm{NdCrO}_{4}$ phase is converted to the $\mathrm{Cr}(\mathrm{III})$ hydroxide phase by incorporation of protons. When the hydroxide is exposed to air at the same temperature, the hydroxyl groups are rapidly degraded by air oxidation and are completely removed in 4 min. Based on the results by XRD, TG and FT-IR, $\mathrm{NdCrO}_{4}$ bulk is reduced by $\mathrm{H}_{2}$ gas at $380^{\circ} \mathrm{C}$ as changing to amorphous $\mathrm{Nd}(\mathrm{III})-\mathrm{Cr}(\mathrm{III})$ hydroxide phase and the hydroxide is easily oxidized in air and reversibly returns to the zircon type oxide by losing hydrogen atoms.

Zircon type $\mathrm{CaCr}^{\mathrm{VI}} \mathrm{O}_{4}$ is thermally stable at temperatures below $800^{\circ} \mathrm{C}$ in air [18]. The lattice parameters of $\mathrm{CaCrO}_{4}(a=0.7222 \mathrm{~nm}, c=0.62851 \mathrm{~nm})$ [19] are close to those of $\mathrm{NdCrO}_{4}(a=0.73107 \mathrm{~nm}, c=0.63999 \mathrm{~nm})$ [16]. In addition, a standard redox potential of $\mathrm{Cr}^{\mathrm{V}}$ and $\mathrm{Cr}^{\mathrm{VI}}$ ions is quite similar each other, as mentioned before. Nevertheless, bulk reduction of $\mathrm{CaCrO}_{4}$ does not occur even at $500^{\circ} \mathrm{C}$. $\mathrm{CaCrO}_{4}$ retains its original zircon-type structure after exposing to $\mathrm{H}_{2}$ gas for $1 \mathrm{~h}$ at $500^{\circ} \mathrm{C}$ (Fig. 1c). Redox titration shows that the average oxidation state of $\mathrm{Cr}$ in the reduced at $500^{\circ} \mathrm{C}$ for $1 \mathrm{~h}$ is almost $6+$. Meanwhile, $\mathrm{Cr} 2 p$ XPS of $\mathrm{CaCrO}_{4}$ shows $2 p_{3 / 2}$ peaks at around $580 \mathrm{eV}$, which is in agreement with the value for $\operatorname{Cr}(\mathrm{VI})$ oxides [20], but the peak shifts to $576 \mathrm{eV}$ after $1 \mathrm{~h}$ reduction at $400^{\circ} \mathrm{C}$. Apparently, the surface of $\mathrm{CaCrO}_{4}$ is reduced by $\mathrm{Cr}(\mathrm{VI}) \rightarrow \mathrm{Cr}(\mathrm{III})$ (Fig. 2b). Fig. 4b is the in situ FT-IR spectra measured during the reduction and re-oxidation cycle. The peak at around $3650 \mathrm{~cm}^{-1}$ is assigned to the second overtone of $\mathrm{CrO}_{4}{ }^{2-}$ stretching band. The hydroxyl groups quickly 
develop by reacting with $\mathrm{H}_{2}$ as is the case with $\mathrm{NdCrO}_{4}$, but the peak intensity of $-\mathrm{OH}$ stretching does not change after 1 min reduction. In addition, the hydroxyl groups are completely removed by $1 \mathrm{~min}$ oxidation. These results indicate that the reduction is terminated by forming the surface $\mathrm{Ca}(\mathrm{II})-\mathrm{Cr}(\mathrm{III})$ hydroxide layer. In $\mathrm{CaCrO}_{4}$, the inner diffusion of electron and proton does not occur.

The reversible transformation behavior of $\mathrm{NdCrO}_{4}$ highlights the feature that the amorphous $\mathrm{Nd}(\mathrm{III})-\mathrm{Cr}(\mathrm{III})$ hydroxide phase is more stable than zircon-type $\mathrm{NdCr}(\mathrm{V}) \mathrm{O}_{4}$ under high hydrogen chemical potential gradients probably due to the high redox potential of $\mathrm{Cr}^{\mathrm{V}}$ ions but the latter is more stable than the former in oxygen atmosphere at elevated temperatures. It is evident that the coupled electron and proton diffusion in $\mathrm{NdCrO}_{4}$ lattice is essential to drive these bulk reactions. Previously, we reported that $\mathrm{NdCrO}_{4}$ exhibited $n$-type semiconductor characteristics in ambient atmosphere, having the conductivity $\sigma$ of $10^{-1} \mathrm{~S} \mathrm{~cm}^{-1}$ order at $400^{\circ} \mathrm{C}$ [21]. Main electron carriers are originated from $\mathrm{d}^{1}$ electron configuration $\mathrm{Cr}(\mathrm{V})$ state. On the other hand, $\mathrm{CaCrO}_{4}$ is reported to be poor electrical conductor, having $\sigma$ of $10^{-5} \mathrm{~S} \mathrm{~cm}^{-1}$ order at $400^{\circ} \mathrm{C}$ due to the $\mathrm{d}^{0}$ electronic configuration of $\mathrm{Cr}(\mathrm{VI})$ valence state [22]. Such difference in the electronic conductivity must attribute to the distinct reactivity between $\mathrm{NdCrO}_{4}$ and $\mathrm{CaCrO}_{4}$.

It has been reported that intermetallic Laves compounds $\mathrm{RM}_{2}$ compounds $(\mathrm{R}=$ a rare earth metal and $\mathrm{M}=\mathrm{Fe}, \mathrm{Co}, \mathrm{Ni}$ ) are hydrogenated to amorphous $\mathrm{RM}_{2} \mathrm{H}_{x}\left({ }_{x} \sim 4\right)$ phase (Hydrogen-induced amorphization, HIA) [23, 24]. If the radii of the tetrahedral holes occupied by $\mathrm{H}$ atoms in $\mathrm{RM}_{2}, r_{\mathrm{h}}$, are larger than the critical value $(0.04 \mathrm{~nm}), \mathrm{RM}_{2}$ tends to be 
hydrogenated. However, the $\mathrm{RM}_{2}$ with $r_{\mathrm{h}}$ of less than the threshold is not hydrogenated (and thus do not cause HIA) because the tetrahedral site is small for the occupation by hydrogen atoms. Protons may occupy an interstitial site in $\mathrm{NdCrO}_{4}$ as is the case with other zircon-type oxides [25], although it is difficult to define precisely the site in zircon-type phase. The free volume of $\mathrm{NdCrO}_{4}$ and $\mathrm{CaCrO}_{4}$ are calculated by using lattice constants and ionic radius [26] to be $51 \%$ and $46 \%$, respectively. Accordingly, it is plausible that $\mathrm{NdCrO}_{4}$ with relatively large free volume is hydrogenated to amorphous hydroxides because it possesses large interstitial spaces for proton occupation. On the other hand, it is speculated the hydrogenated $\mathrm{CaCrO}_{4}$ is not thermodynamically stable due to the relatively small interstitial space and thus the bulk reduction is not progressive.

In the reduction of $\mathrm{NdCrO}_{4}$, protons diffuse inward across the amorphized, hydroxide layer, so that the diffusivity of this layer may limit the rate of proton insertion. However, the protons must diffuse inside the restored $\mathrm{NdCrO}_{4}$ lattice during re-oxidation in order to release proton and electron for the water forming reaction at the surface. The restoration to zircon phase by oxidation is rather fast, indicating that $\mathrm{NdCrO}_{4}$ exhibits fast proton conduction in ambient atmosphere.

The gas concentration cell experiments are a powerful technique to determine the transport number of ion and electron carriers. Unfortunately, it is difficult to obtain the dense pellets with gas-tightness and durability for the electrochemical measurements, because $\mathrm{NdCrO}_{4}$ is easily pyrolyzed to perovskite-type $\mathrm{NdCrO}_{3}$ at temperatures above $600^{\circ} \mathrm{C}$ even in air [16]. In order to clarify the proton diffusivity, we examined here the proton conducting ceramic fuel 
cell (PCFC) with a $\mathrm{NdCrO}_{4}$ interlayer between $\mathrm{BaZr}_{0.1} \mathrm{Ce}_{0.7} \mathrm{Y}_{0.2} \mathrm{O}_{3}$ (BZCY) electrolyte and $\mathrm{La}_{0.8} \mathrm{Sr}_{0.2} \mathrm{Co}_{0.5} \mathrm{Fe}_{0.5} \mathrm{O}_{3}$ (LSCF) cathode. Such a cell may generate electricity, if the $\mathrm{NdCrO}_{4}$ interlayer enables proton transfer from BZCY electrolyte to LSCF cathode.

Figure 5 shows a cross-section SEM of the $\mathrm{NdCrO}_{4}$ film formed on a $\mathrm{Si}$ wafer by screenprinting with as-prepared paste. The layer consists of the oxide grains with a length of several hundred nanometers and is uniformly formed over the surface with a thickness of about $\sim 10 \mu \mathrm{m}$. Figure 6 shows the fuel cell performance at $500^{\circ} \mathrm{C}$ for the cell with $\mathrm{NdCrO}_{4}$ inter layer prepared by the same method. The cell without $\mathrm{NdCrO}_{4}$ interlayer shows the open circuit voltage (OCV) of $1.1 \mathrm{~V}$ and the maximum power density of $13 \mathrm{~mW} \mathrm{~cm}{ }^{-1}$. The current voltage curve is almost linear, indicating that the limited power density of our cell is due to the large ohmic loss at the relatively thick electrolytes.

$\mathrm{NdCrO}_{4}$ cell poses remarkable power generation at $500^{\circ} \mathrm{C}$, giving the $\mathrm{OCV}$ of $1.1 \mathrm{~V}$ and the peak power density of $11 \mathrm{~mW} \mathrm{~cm}{ }^{-2}$. In a separate experiment, the cells with $\mathrm{NdCrO}_{4}$ interlayer and Au current collector electrode at cathode side were fabricated by similar method. The cell did not give an apparent OCV, indicating that $\mathrm{NdCrO}_{4}$ cannot electrocatalyze the oxygen reduction reaction (ORR). The ORR must proceed predominantly at $\mathrm{LSCF}$ in a Pt|BZCY $\mid \mathrm{NdCrO}_{4} / \mathrm{LSCF}$ cell. These results suggest that $\mathrm{NdCrO}_{4}$ interlayer mainly contribute to pump out protons from electrolyte to TPB boundary. The performance of the $\mathrm{NdCrO}_{4}$ cell is quite similar to that of the cell without $\mathrm{NdCrO}_{4}$ interlayer, disclosing that the resistance for the proton migration in $\mathrm{NdCrO}_{4}$ layer is not rate limiting in the current cell setup. 
Previously, we conducted acceptor-doping into $\mathrm{NdCrO}_{4}$ by Ca substitution of $\mathrm{Nd}$ sites, where the lack of positive charge was compensated by forming electron hole carriers, namely oxidation of $\mathrm{Cr}(\mathrm{V})$ to $\mathrm{Cr}(\mathrm{IV})$ [27]. Accordingly, it is difficult to consider as-prepared $\mathrm{NdCrO}_{4}$ have protonic carriers generated by acceptor impurities. Thus, the protonic carriers in the interlayer is given by the reduction-induce proton insertion (Eq. 1). $\mathrm{NdCrO}_{4}$ near $\mathrm{BZCY}$ electrolyte might be converted to the $\mathrm{Cr}(\mathrm{III})$ hydroxide phase owing to the high $\mathrm{H}^{+}$ concentration gradients formed at the interface with electrolyte. However, the hydroxides are immediately oxidized to the original oxide phase under the oxygen-rich atmosphere at cathode. In the re-oxidation process, proton and electrons are released from the hydroxide/oxide reaction front and they will diffuse in $\mathrm{NdCrO}_{4}$ matrices towards air-LSCF-NdCrO 4 three phase boundary (TPB) for water forming reaction. Hence protons are pumped out from electrolyte to cathode as the reduction and re-oxidation cycle is progressive during fuel cell operation

Current results mentioned above are not surprising in view of structural and electrochemical features of $\mathrm{NdCrO}_{4}$. Amezawa et al has reported that zircon-type Ca-dope $\mathrm{YPO}_{4}$ reveals proton conductivity in wet atmosphere [28]. $\mathrm{H}^{+}$carriers involved by acceptor-doping can migrate within the lattice by thermally-activated jump from one phosphate anion to the neighbor. $\mathrm{NdCrO}_{4}$ with relatively large free volume is speculated to have the similar pathway for proton carriers. As mentioned above, the redox potential of $\mathrm{Cr}(\mathrm{V}$ $\rightarrow \mathrm{III})$ is $1.32 \mathrm{~V}$ vs NHE and is higher than that of the oxygen reduction potential $(1.23 \mathrm{~V}$ vs NHE). This feature may enable reduction to Cr(III) hydroxide phase under cathodic potential 
of operating fuel cell.

\section{Conclusion}

In summary, $\mathrm{NdCrO}_{4}$ causes bulk reduction through the reactions with $\mathrm{H}_{2}$ gas at around $400^{\circ} \mathrm{C}$, changing to amorphous $\mathrm{Nd}(\mathrm{III})-\mathrm{Cr}(\mathrm{III})$ hydroxide phase by proton incorporation. This hydroxide phase can recover to the original zircon type oxide phase by air oxidation at the same temperature region. The mixed proton and electron conductivity of $\mathrm{NdCrO}_{4}$ phase is essential to the bulk redox reactions. Therefore, poor electrical conducting $\mathrm{CaCrO}_{4}$ does not show such bulk reduction although the crystal structure and the redox potential are very similar to those of $\mathrm{NdCrO}_{4}$. $\mathrm{NdCrO}_{4}$ film deposited on a BZCY electrolyte undergoes the redox cycling under the cathodic conditions of operating PCFC, because $\mathrm{NdCrO}_{4}$ moieties near the interface with electrolyte change to the corresponding hydroxide phase by the high proton concentration gradient but the formed hydroxide is immediately re-oxidized to $\mathrm{NdCrO}_{4}$ as accompanied by inner diffusion of electron and proton towards gas-LSCF-NdCrO 4 TPB. Hence, the PCFC having $\mathrm{NdCrO}_{4}$ interlayer between cathode and electrolyte can give remarkable power generation at $500^{\circ} \mathrm{C}$ giving $\mathrm{OCV}$ of more than $1.0 \mathrm{~V}$. The unique reactivity of $\mathrm{NdCrO}_{4}$ is attributed to the coexistence of large interstitial space for hydrogen occupation and singular electronic states of the $\mathrm{Cr}^{\mathrm{V}}$ ion in $\mathrm{NdCrO}_{4}$.

\section{Acknowledgement}


This work was supported by PRESTO-JST 'Creation of Innovative Core Technology for Manufacture and Use of Energy Carriers from Renewable Energy’. 


\section{References}

1. S, Licht and R. T.-Vered, Chem. Commun. 40 (2004) 628.

2. S, Licht, B. Wang and S. Ghosh, Science 285 (1999) 1039.

3. M. C. Ghosh and E. S. Gould, J. Am. Chem. Soc. 115 (1993) 3167.

4. E. Gould, Acc. Chem. Res. 19 (1986) 66.

5. S. I. Brauer and K. Wetterhahn, J. Am. Chem. Soc. 113 (1991) 3001.

6. B. M. Weckhuysen, I. E. Wachs and R. A. Schoonheydt, Chem. Rev. 96 (1996) 3327.

7. M. W. Kanan, J. Yano, Y. Surendranath, M. Dinca, V. K. Yachandra and D. G. Nocera, J. Am. Chem. Soc. 132 (2010) 13692.

8. J. Hu, T. Xing, Q. Jia, H. Hao, D. Yang, Y. Guo and X. Hu, Appl. Catal. A 306 (2006) 29.

9. R. Saéz-Puche, E. Jiménez, J. Isasi, M.T. Fernández-Dıáz and J.L. Garcrá-Munõzc, J. Solid State Chem. 171 (2003) 161.

10. E. Jiménez, J. Isasi and R. Saéz-Puche, J. Alloys Comp. 312 (2000) 53.

11. Y. Aoki, H. Habazaki and H. Konno, Chem. Mater. 15 (2003) 2419.

12. Y. Aoki, H. Habazaki and H. Konno, Chem. Lett. 33 (2004) 992.

13. A.Unemoto, A. Kaimai, K. Sato, K. Yashiro, H. Matsumoto, J. Mizusaki, K. Amezawa and T. Kawada, Solid State Ionics 178 (2008) 1663.

14. H. Matsumoto, T. Shimura, T. Higuchi, H. Tanaka, K. Katahira, T. Otake, T. Kudo, K. Yashiro, A. Kaimai, T. Kawada and J. Mizusaki, J. Electrochem. Soc. 152 (2005) A488.

15. A. J. Bard, R. Parsons, J. Jordan, Standard Potentials in Aqueous Solution, Marcel 
Dekker, New York, 1985.

16. Y. Aoki, H. Konno, H. Tachikawa and M. Inagaki, Bull. Chem. Soc. Jpn. 73 (2000) 1197.

17. T. P. Moffat and R. M. Ratanision, J. Electrochem. Soc. 139 (1992) 1869.

18. K. T. Adendorff, J. P. R. de Villiers and G. J. Kruger, J. Am. Ceram. Soc. 75 (1992) 1416.

19. L. Li, W. Yu, Y. Long and C. Jin, Solid State Commun. 137 (2006) 358.

20. D. Shuttleworth, J. Phys. Chem. 84 (1980) 1629.

21. Y. Aoki, H. Konno and H. Tachikawa J. Mater. Chem. 11 (2001) 1214.

22. I. Yasuda and M. Hishinuma, Solid State Ionics 78 (1995) 109.

23. K. Aoki, X-G. Li and T. Matsumoto, Acta Metall. Mater. 40 (1992) 1717.

24. K. Aoki, T. Yamamoto and T. Matsumoto, Scripta Metall. 21 (1987) 27.

25. I. Saadoune, J. A. Purton and N. H. de Leeuw, Chem. Geo. 258 (2009) 182.

26. R. D. Shannon and C. T. Prewitt, Acta Crystallogr. B25 (1969) 925.

27. Y. Aoki and H. Konno, J. Solid State Chem. 156 (2001) 370.

28. K. Amezawa, Y. Tomii and N. Yamamoto, Solid State Ionics, 162-163 (2003) 175. 


\section{Figure captions}

Fig. 1 (a) XRD patterns of $\mathrm{NdCrO}_{4}$ kept at various temperatures for $20 \mathrm{~min}$ in $\mathrm{H}_{2}$ atmosphere.

(b) $\mathrm{XRD}$ patterns of $\mathrm{NdCrO}_{4}$ specimens reduced at $380^{\circ} \mathrm{C}$ in $\mathrm{H}_{2}$ and re-oxidized at $380^{\circ} \mathrm{C}$ in air in various reaction times. Red patterns show the reduced specimens and blue ones the re-oxidized. (c) XRD patterns of $\mathrm{CaCrO}_{4}$ kept at various temperatures for $1 \mathrm{~h}$ in $\mathrm{H}_{2}$ atmosphere. (d) $\mathrm{TEM}$ of $\mathrm{NdCrO}_{4}$ powder reduced at $380^{\circ} \mathrm{C}$ for 20 min in $\mathrm{H}_{2}$. Inset is the corresponding SAED patterns at the pints in TEM image.

Fig. $2 \mathrm{Cr} 2 \mathrm{p}$ XPS spectra of (a) $\mathrm{NdCrO}_{4}$ and (b) $\mathrm{CaCrO}_{4}$. Black spectra show the as-prepared and Red the reduced in $\mathrm{H}_{2}$ at $380^{\circ} \mathrm{C}$ for 20 min with $\mathrm{NdCrO}_{4}$ and $400^{\circ} \mathrm{C}$ for $1 \mathrm{~h}$ with $\mathrm{CaCrO}_{4}$.

Fig. 3 (a) Thermal gravimetry of $\mathrm{NdCrO}_{4}$ measured in $\mathrm{H}_{2}$ by raising temperature at $10^{\circ} \mathrm{C}$ $\min ^{-1}$ in the range of 25 to $1000^{\circ} \mathrm{C}$. (b) Weight transient curve of $\mathrm{NdCrO}_{4}$ kept in $\mathrm{H}_{2}$ at $380^{\circ} \mathrm{C}$. The atmosphere is switched from pure Ar to $\mathrm{H}_{2}$ at the point indicated by blue dashed line.

Fig. 4 In situ FT-IR of (a) $\mathrm{NdCrO}_{4}$ and (b) $\mathrm{CaCrO}_{4}$ during reduced at $380^{\circ} \mathrm{C}$ in $\mathrm{H}_{2}$ and re-oxidized at $380^{\circ} \mathrm{C}$ in air after 30 min reduction. In (a) and (b), Red spectra show the reduced and blue ones the reoxidized. Numbers beside the panels show reduction and re-oxidation time. The sharp peak near $3350 \mathrm{~cm}^{-1}$ is the noise from detector. In (b), the peak at around $3650 \mathrm{~cm}^{-1}$ is assigned to the second overtone of $\mathrm{CrO}_{4}{ }^{2-}$ stretching band. 
Fig. 5 Cross-section SEM of $\mathrm{NdCrO}_{4}$ layer deposited on Si wafer by screen-printing method.

Fig. 6 Fuel cell performances of PCFC with a $\mathrm{NdCrO}_{4}$ interlayer (red) and without the interlayer (black) at $500^{\circ} \mathrm{C}$. 


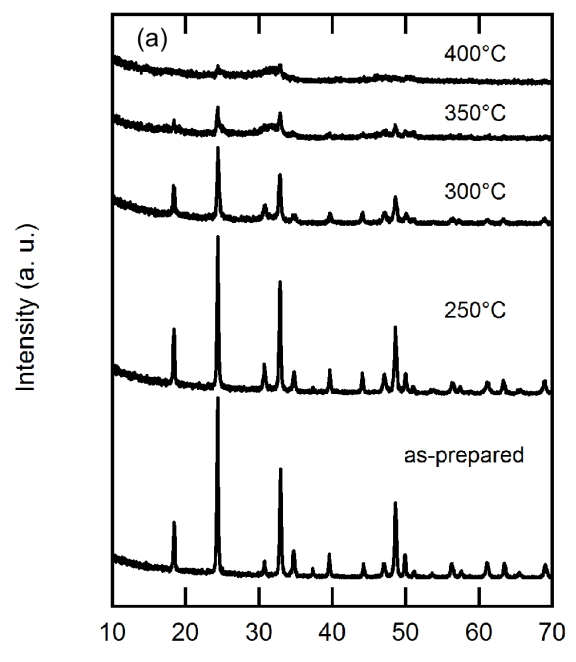

$2 \theta(\mathrm{CuK} \alpha)\left({ }^{\circ}\right)$

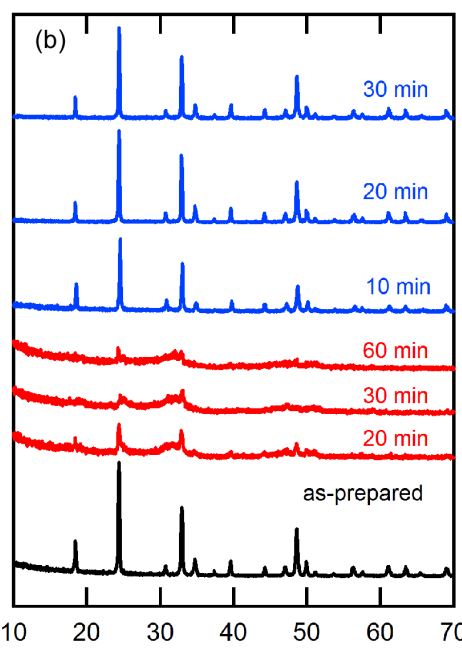

$2 \theta(\mathrm{CuK} \alpha)\left({ }^{\circ}\right)$

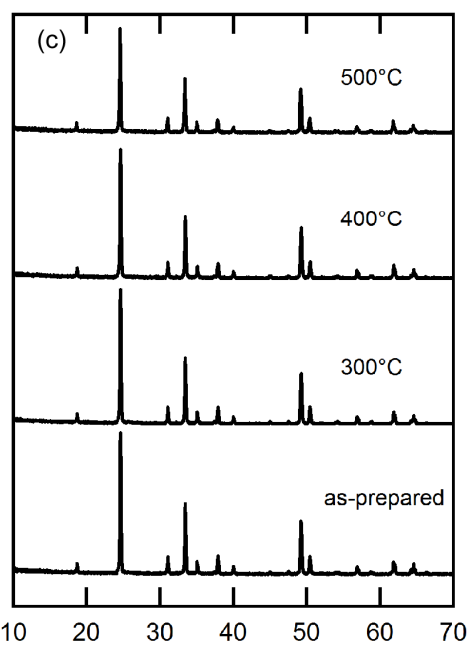

$2 \theta(\mathrm{CuK} \alpha)\left(^{\circ}\right)$

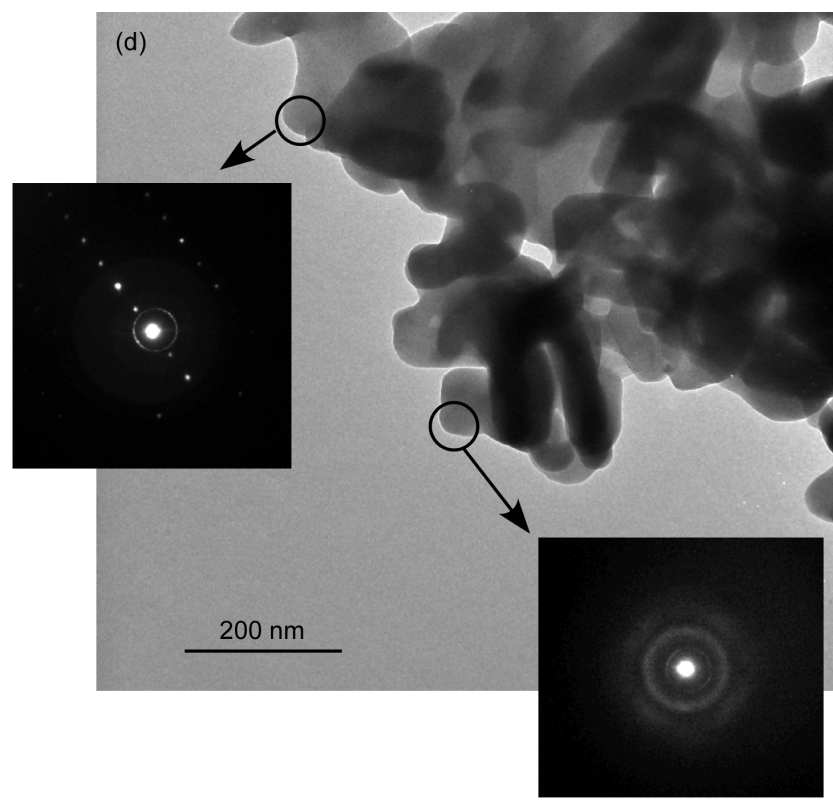

Fig. 1 (a) XRD patterns of $\mathrm{NdCrO}_{4}$ kept at various temperatures for $20 \mathrm{~min}$ in $\mathrm{H}_{2}$ atmosphere. (b) XRD patterns of $\mathrm{NdCrO}_{4}$ specimens reduced at $380^{\circ} \mathrm{C}$ in $\mathrm{H}_{2}$ and re-oxidized at $380^{\circ} \mathrm{C}$ in air in various reaction times. Red patterns show the reduced specimens and blue ones the re-oxidized. (c) XRD patterns of $\mathrm{CaCrO}_{4}$ kept at various temperatures for $1 \mathrm{~h}$ in $\mathrm{H}_{2}$ atmosphere. (d) $\mathrm{TEM}$ of $\mathrm{NdCrO}_{4}$ powder reduced at $380^{\circ} \mathrm{C}$ for 20 min in $\mathrm{H}_{2}$. Inset is the corresponding SAED patterns at the pints in TEM image. 


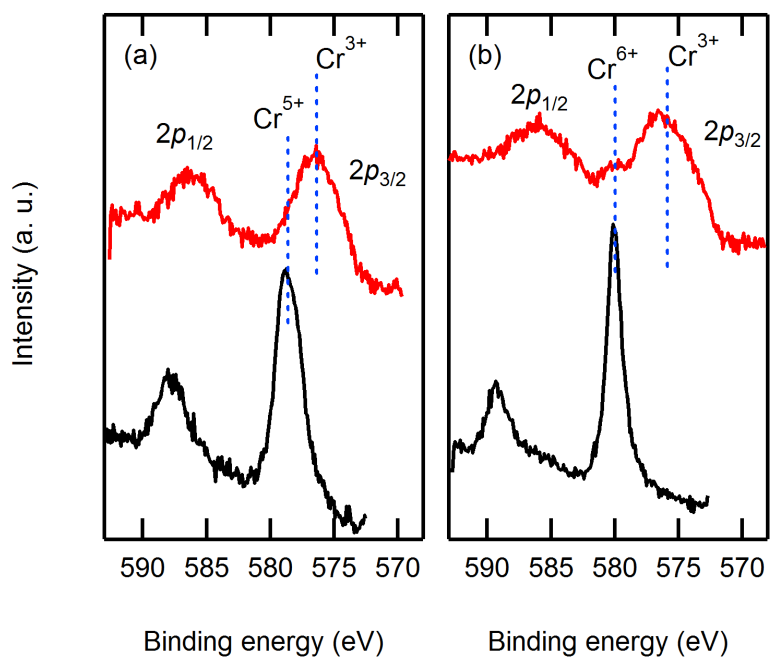

Fig. 2 Cr 2p XPS spectra of (a) $\mathrm{NdCrO}_{4}$ and (b) $\mathrm{CaCrO}_{4}$. Black spectra show the as-prepared and Red the reduced in $\mathrm{H}_{2}$ at $380^{\circ} \mathrm{C}$ for 20 min with $\mathrm{NdCrO}_{4}$ and $400^{\circ} \mathrm{C}$ for 1 h with $\mathrm{CaCrO}_{4}$. 

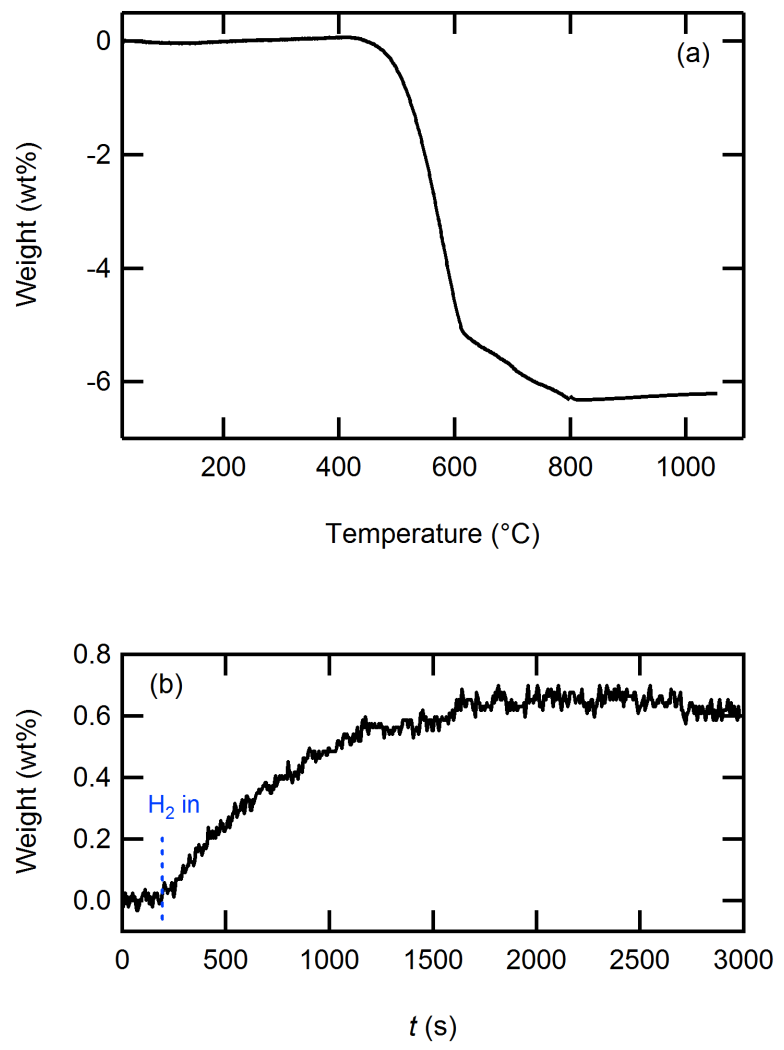

Fig. 3 (a) Thermal gravimetry of $\mathrm{NdCrO}_{4}$ measured in $\mathrm{H}_{2}$ by raising temperature at $10^{\circ} \mathrm{C}$ $\min ^{-1}$ in the range of 25 to $1000^{\circ} \mathrm{C}$. (b) Weight transient curve of $\mathrm{NdCrO}_{4}$ kept in $\mathrm{H}_{2}$ at $380^{\circ} \mathrm{C}$. The atmosphere is switched from pure Ar to $\mathrm{H}_{2}$ at the point indicated by blue dashed line. 

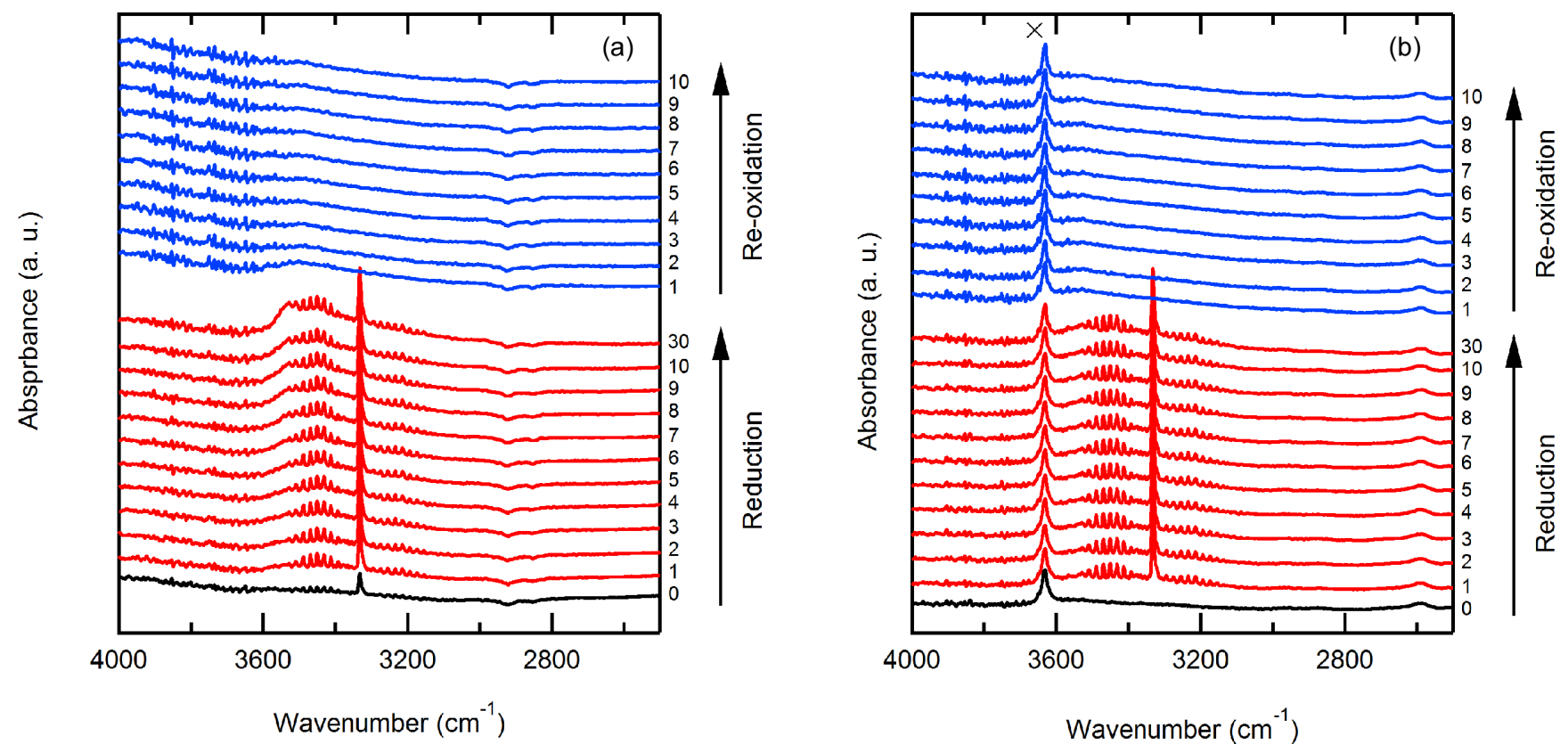

Fig. 4 In situ FT-IR of (a) $\mathrm{NdCrO}_{4}$ and (b) $\mathrm{CaCrO}_{4}$ during reduced at $380^{\circ} \mathrm{C}$ in $\mathrm{H}_{2}$ and re-oxidized at $380^{\circ} \mathrm{C}$ in air after 30 min reduction. In (a) and (b), Red spectra show the reduced and blue ones the reoxidized. Numbers beside the panels show reduction and re-oxidation time. The sharp peak near $3350 \mathrm{~cm}^{-1}$ is the noise from detector. In (b), the peak at around $3650 \mathrm{~cm}^{-1}$ is assigned to the second overtone of $\mathrm{CrO}_{4}{ }^{2-}$ stretching band. 


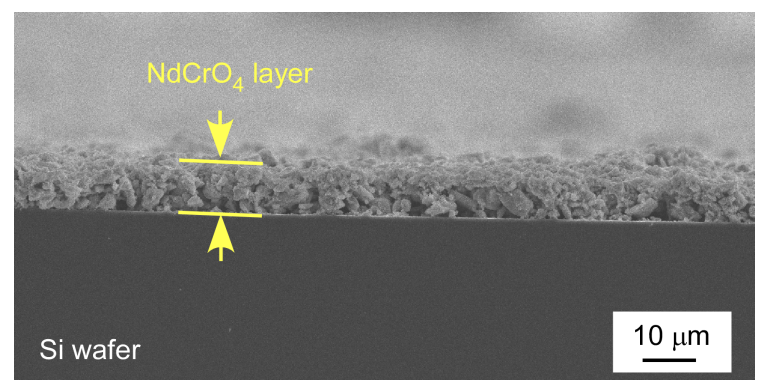

Fig. 5 Cross-section SEM of $\mathrm{NdCrO}_{4}$ layer deposited on Si wafer by screen-printing method. 


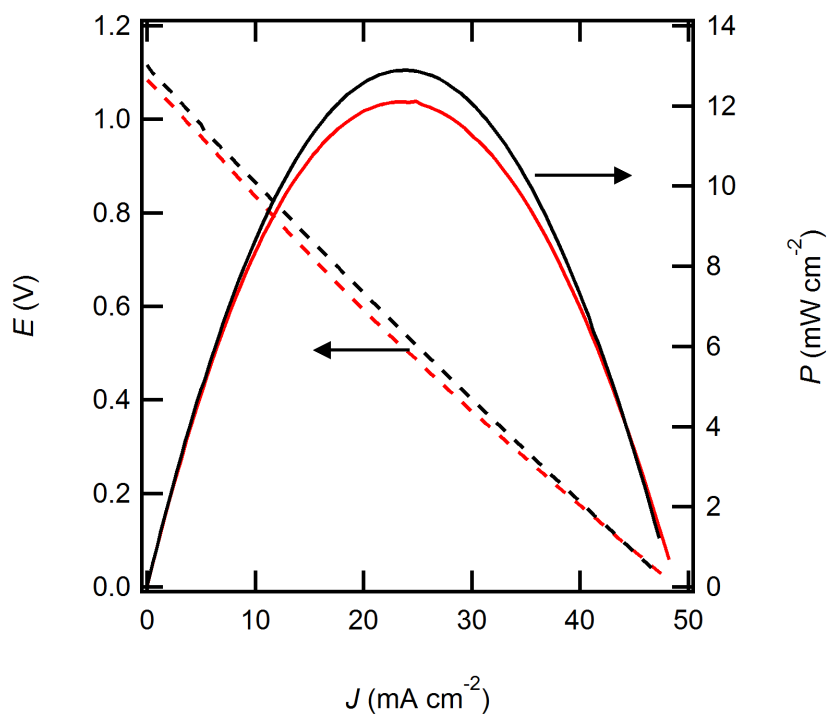

Fig. 6 Fuel cell performances of PCFC with $\mathrm{NdCrO}_{4}$ interlayer (red) and without the interlayer (black) at $500^{\circ} \mathrm{C}$. 